\title{
$\beta 2$-Containing Nicotinic Receptors Contribute to the Organization of Sleep and Regulate Putative Micro-Arousals in Mice
}

\author{
Clément Léna, ${ }^{1}$ Daniela Popa, ${ }^{2}$ Régis Grailhe, ${ }^{1}$ Pierre Escourrou, ${ }^{3}$ Jean-Pierre Changeux, ${ }^{1}$ and Joëlle Adrien ${ }^{2}$ \\ ${ }^{1}$ Récepteurs et Cognition, Unité de Recherche Associée Centre National de la Recherche Scientifique, Institut Pasteur, 757242 Paris Cedex 15, France, \\ ${ }^{2}$ Neuropsychopharmacologie Moléculaire Cellulaire et Fonctionnelle, Institut National de la Santé et de la Recherche Médicale, 75634 Paris Cedex 13 , \\ France, and ${ }^{3}$ Laboratoire de Neuropharmacologie, Faculté de Pharmacie, 92296 Chatenay-Malabry Cedex, France
}

The cholinergic system is involved in arousal and in rapid eye movement sleep (REMS). To evaluate the contribution of nicotinic acetylcholine receptors (nAChRs) to these functions, we studied with polygraphic recordings the regulation of sleep in mice lacking the $\beta 2$ subunit gene of the nAChRs, a major component of high-affinity nicotine binding sites in the brain. Nicotine (1-2 mg/kg, i.p.) increased wakefulness in wild-type but not knock-out animals, indicating that $\beta 2$-containing nAChRs mediate the arousing properties of nicotine. Under normal conditions, the $\beta 2-/-$ mice displayed the same amounts of waking, non-REM sleep (NREMS) and REMS as their wild-type counterparts. However, they exhibited longer REMS episodes and a reduced fragmentation of NREMS by events characterized notably by a transient drop in EEG power and frequently associated with EMG activation, tentatively referred to as micro-arousals. Respiration monitoring showed that these events were accompanied with, but not caused by, breathing irregularities. Sleep deprivation of $\beta 2-/-$ mice resulted in a normal increase in REMS episode duration and NREMS $\delta$ power but yielded a reduction of the number of micro-arousals in NREMS. In contrast, in $\beta 2-/-$ mice, a $1 \mathrm{hr}$ immobilization stress failed to produce the normal rebound in REMS in the following $12 \mathrm{hr}$ and, instead, was associated with increased NREMS fragmentation and sustained corticosterone levels. Our results show that the $\beta 2$-containing $\mathrm{nAChRs}$ contribute to the organization of sleep by regulating the transient phasic activity in NREMS, the REMS onset and duration, and the REMS-promoting effect of stress.

Key words: nicotinic receptors; sleep; arousal; mice; sleep deprivation; stress

\section{Introduction}

The regulation of the sleep-wake cycle is a complex process involving several brain structures and neurotransmitters (Steriade and McCarley, 1990; Pace-Schott and Hobson, 2002). The cholinergic system is classically considered to be a positive effector of rapid eye movement sleep (REMS) at the pontine level (Sakai et al., 2001) and to contribute to cortical arousal through its ascending component (Sarter and Bruno, 2000; Jones, 2003). Indeed, acetylcholine (ACh) release in the forebrain is higher during REMS and wake (Jasper and Tessier, 1971; Marrosu et al., 1995). The contribution of nicotinic ACh receptors (nAChRs) to this dual function of the cholinergic system is still primarily unknown.

Received July 1, 2003; revised April 14, 2004; accepted April 16, 2004.

This research was supported by the Collège de France, Commission of the European Communities, Institut $\mathrm{Na}$ tional de la Santé et de la Recherche Médicale, Centre National de la Recherche Scientifique, and Association pour la Recherche sur le Cancer. D.P. and R.G. were supported by a grant from la Fondation pour la Recherche Médicale and from la Ligue Contre le Cancer. We thank Dr. B. Boutrel and E. Mouisel for their help with the surgery and the plethysmograph, respectively, and M. Hamon for critical reading of this manuscript.

Correspondence should be addressed to Dr. Joëlle Adrien, Neuropsychopharmacologie Moléculaire Cellulaire et Fonctionnelle, Institut National de la Santé et de la Recherche Médicale Unité 288, 91 bd de l'Hopital, 75634 Paris Cedex 13, France. E-mail: adrien@ext.jussieu.fr.

C. Léna's present address: Centre National de la Recherche Scientifique Unité Mixte de Recherche 8544, 46 rue d'Ulm, 75005 Paris, France.

DOI:10.1523/JNEUROSCI.3882-03.2004

Copyright $\odot 2004$ Society for Neuroscience $\quad 0270-6474 / 04 / 245711-08 \$ 15.00 / 0$
Nicotine intake has long been known to cause cortical electroencephalography (EEG) desynchronization (Yamamoto and Domino, 1965). Nicotine increases arousal and attention (Lawrence et al., 2002; Levin, 2002), and the nicotinic antagonist mecamylamine causes drowsiness and decreases the performance in attention-demanding tasks (Pickworth et al., 1997). Although nicotine injections acutely increase waking, chronic nicotine treatment results in higher amounts of REMS (Salin-Pascual et al., 1999), indicating that nAChRs may intervene at different levels in the control of vigilance. Moreover, mutations in the $\alpha 4$ and $\beta 2$ subunits of $\mathrm{nAChRs}$ have been linked to nocturnal frontal lobe epilepsies that occur during light slow-wave sleep (Sutor and Zolles, 2001). The importance of nAChRs in sleep regulation has also been suggested by their implication in the sudden infant death syndrome (SIDS) (Slotkin, 1998).

The nAChRs are pentameric ligand-gated ion channels with subunits that are encoded by 10 different genes in the nervous system (Le Novère et al., 2002). Mice lacking the $\beta 2$ subunit gene $(\beta 2-/-$ mice $)$ are devoid of high-affinity nicotine binding sites in the CNS (Picciotto et al., 1995; Zoli et al., 1998) and exhibit a loss or reduction of nicotine-elicited currents in neurons from various brain regions (Picciotto et al., 1995; Zoli et al., 1998; Marubio et al., 1999; Klink et al., 2001). Therefore, these mice offer the opportunity to investigate the contribution of nAChRs 
to sleep and wakefulness. Indeed, recent work has demonstrated that, compared with wild-type (WT) mice, they exhibit an increased ventilatory response to a hypoxic challenge in sleep associated with a reduction of transient movements, which suggests that nAChRs contribute to awakening under these conditions (Cohen et al., 2002). The present study aims at testing the involvement of nAChRs in the regulation of vigilance stages and in breathing pattern during sleep. For this purpose, we performed polygraphic recordings in $\beta 2-/-$ and WT mice under baseline conditions, as well as in response to nicotine injections and to behavioral manipulations (sleep deprivation and immobilization stress) known to alter sleep patterns (Boutrel et al., 2002).

\section{Materials and Methods}

Animals. The animals used were adult male, age-matched, WT and homozygous $\beta 2-/-$ mice deleted for the $\beta 2 \mathrm{nAChR}$ subunit gene. Specifically, C57BL/6J mice (IFFA-Credo, Les Oncins, France) were compared with $\beta 2-/-$ mutant siblings from parents backcrossed for 12 generations to C57BL/6J inbred mice. The animals were housed under a $12 \mathrm{hr}$ light/dark (lights on 7:00 A.M. to 7:00 P.M.) cycle with ad libitum food and water. All experiments followed the European Economic Community (EEC) Directive (86/609/EEC), and every effort was made to minimize the number of animals used and any pain and discomfort.

Surgical procedure. Animals were implanted under xylazine/ketamine anesthesia (5 and $100 \mathrm{mg} / \mathrm{kg}$, i.p., respectively). The electrodes were made of enameled nichrome wire (diameter, $100 \mu \mathrm{m}$ ). These electrodes were positioned in holes perforated in the skull $(1 \mathrm{~mm}$ caudal and $1 \mathrm{~mm}$ lateral to bregma, and medial reference electrode $1 \mathrm{~mm}$ caudal to $\lambda$ ) for epidural EEG. A pair of nichrome wire electrodes (with the insulant removed over $\sim 1 \mathrm{~mm}$ ) was inserted in the neck muscles for electromyographic (EMG) recording (Boutrel et al., 1999). A fraction of the animals also received a pair of subcutaneous stainless steel electrodes located under the chest and at the level of the tail for electrocardiogram (ECG) recordings in the plethysmograph experiments. The animals were allowed to recover at least $10 \mathrm{~d}$ after the surgical procedure.

Recordings. The mice were connected to the recording system with a light-weight cable and a swivel allowing free movements in the cage. Animals were recorded by groups of four, usually two WT and two $\beta 2-/-$ mice. The signals were fed into an Embla device (Medcare, Reykjavik, Iceland) for differential amplification, sampled at $100 \mathrm{~Hz}$ (EEG, pressure signal in plethysmographic experiments) or $200 \mathrm{~Hz}$ (EMG, ECG), and recorded with the software Somnologica (Medcare, Reykjavik, Iceland). Recordings started after a $48 \mathrm{hr}$ habituation period and were collected during 48 consecutive hours for analysis of basal sleepwaking patterns.

Sleep deprivation was performed by moving the cage into a new room and by enriching the cage with new objects during $6 \mathrm{hr}$ (7:00 A.M. to 1:00 P.M.). The animals were visually monitored and new stimuli were added, or the animals were gently handled when behavioral signs of drowsiness were observed. The immobilization stress was performed by wrapping the mice in a nylon-covered metal mesh during $1 \mathrm{hr}$ (6:00-7:00 P.M.). Matched control recordings were obtained for each animal by disconnecting and reconnecting back the animals to the recording leads at the same time of the day as in the sleep deprivation and immobilization stress conditions. These controls were performed first, and in all cases, the two protocols were inter-spaced by at least 1 week. For pharmacological experiments, animals received the drug (nicotine bitartrate in saline injected intraperitoneally) at 10:00 A.M. Two successive injections of nicotine were separated by at least $2 \mathrm{~d}$. Most animals underwent either the deprivation and stress protocols or the pharmacological treatments; otherwise, the drug injections were always performed last.

Plethysmography. Respiration was monitored with a two-chambers, constant-flow plethysmograph (Jacky, 1978) equipped with a pressure transducer (DP45; Validyne, Northridge, CA) and a swivel for combined polygraphic recordings. The outflow gas concentrations of oxygen and carbon dioxide were continuously monitored by a Capnomac Ultima (Datex, Helsinki, Finland) and maintained within physiological range. All of the signals were recorded with the same Embla device as above. The recordings were performed between 10:00 A.M. and 4:00 P.M. Cycle by cycle tidal volume and breathing period were evaluated with custom Matlab (MathWorks, Natick, MA) routines. "Sighs” were isolated as single respiratory cycles of amplitude higher than two times the average amplitude over a baseline taken over the 30 preceding cycles $(\sim 10 \mathrm{sec})$ and followed by a pause; this criterion corresponds approximately to events deviating more than five times the SD of the cycle amplitude. The respiratory pause that followed immediately after the sighs qualified as an apnea (see below) in only $5-15 \%$ of the cases. Apnea is defined as cessation of breathing during at least twice the average respiratory cycle duration in non-REM sleep (NREMS). Apneas were scored independently from desaturation events. The measurement of effort was not recorded; however, it is only required to determine the mechanism of the apneas (Martin et al., 1985). Because a large fraction of apnea occurred in the seconds following a sigh, we considered separately "spontaneous apnea," defined as apnea not preceded by sighs in the preceding $15 \mathrm{sec}$. The respiratory flow is the ratio of tidal volume over the respiratory cycle duration. The traces of each candidate sigh and apnea were visually inspected to avoid artifacts. We only considered sighs and apneas in NREMS. The heart rate was obtained from the R-R intervals in the ECG.

Serum corticosterone assay. Serum corticosterone levels were measured immediately and $4 \mathrm{hr}$ after the immobilization stress (6:00-7:00 P.M.). For this purpose, animals were decapitated, and blood was collected and centrifuged at $4000 \mathrm{rpm}\left(4^{\circ} \mathrm{C}\right)$ for $25 \mathrm{~min}$. Separated serum was stored at $-20^{\circ} \mathrm{C}$ until additional analysis. Corticosterone was quantified by radioimmunoassay (ICN Biochemicals, Orsay, France).

Scoring and analysis. The three vigilance states, wake, NREMS, and REMS, were scored manually by $15 \mathrm{sec}$ segments using primarily the power spectrum of EEG as well as the EMG activity (Fig. 1). WT and $\beta 2-/-$ animals had similar EEG power spectra across the different vigilance stages, consistent with the spectra published for C57BL/6 J mice (Fig. 1C) (Franken et al., 1998; Huber et al., 2000). We also scored events in NREMS corresponding to $5-15 \mathrm{sec}$ drop of at least $50 \%$ of the EEG power with a spectral content mostly in the $\delta$ band $(1-5 \mathrm{~Hz})$. These events were scored as micro-arousals (MA) (see Discussion). They are distinct from single episodes in NREMS, where the EEG spectral content increases in the $\theta$ band $(6-9 \mathrm{~Hz})$ with an EMG activation and that were thus scored as "short awakenings" and counted as Wake. Events corresponding to our short awakenings and micro-arousals are presumably pooled into "brief awakenings" in other studies in the rat (Franken et al., 1991) and in the mouse (Tobler et al., 1996; Franken et al., 1999). The reliability of the score was assessed by two different persons scoring independently $24 \mathrm{hr}$ from one WT and one $\beta 2-/-$ mouse and yielded a correspondence of $95 \%$ in the score (WT, $95.5 \%$; $\beta 2-/-, 95.7 \%)$. The accuracy of the estimates of sleep state amount and duration was verified by rescoring with a resolution of $5 \mathrm{sec}, 6 \mathrm{hr}$ of recordings from seven WT and seven $\beta 2-/-$; the average difference in amounts and episode durations (estimated over periods of $3 \mathrm{hr}$ as in most of the present study) between the $5 \mathrm{sec}$ score and the $15 \mathrm{sec}$ score was in the interval of $\pm 3 \%$. The analysis was made using Matlab (MathWorks) routines and $\mathrm{R}$ (http://cran.r-project.org/mirrors.html), a free implementation of S-plus, for statistical analysis. Amounts and durations were evaluated over $3 \mathrm{hr}$ intervals. Significance was tested by performing an ANOVA using a linear mixed effect model with repeated measures over time ( $3 \mathrm{hr}$ segments) and treatment (sleep deprivation, stress), when appropriate, followed by unpaired or paired $t$ tests as needed. The symbols used in the figures indicate the following: ${ }^{\star} p<0.5,{ }^{* *} p<0.01,{ }^{* * *} p<0.001$ for paired $t$ tests (control vs treatment); and ${ }^{\dagger} p<0.05,{ }^{\dagger \dagger} p<0.01,{ }^{\dagger \dagger} p<$ 0.001 for unpaired $t$ tests (difference in genotypes). Symbols in parenthesis are used to indicate significant $t$ test probabilities but nonsignificant ANOVA. Data are presented as mean \pm SEM.

\section{Results}

\section{Nicotine injections transiently increase wakefulness in WT} but not in $\beta 2-/-$ mice

In WT animals, nicotine at $1-2 \mathrm{mg} / \mathrm{kg}$, intraperitoneally, caused a significant increase in the amounts of wakefulness in the first hour after the injection (Fig. 2). These doses of nicotine also 
A
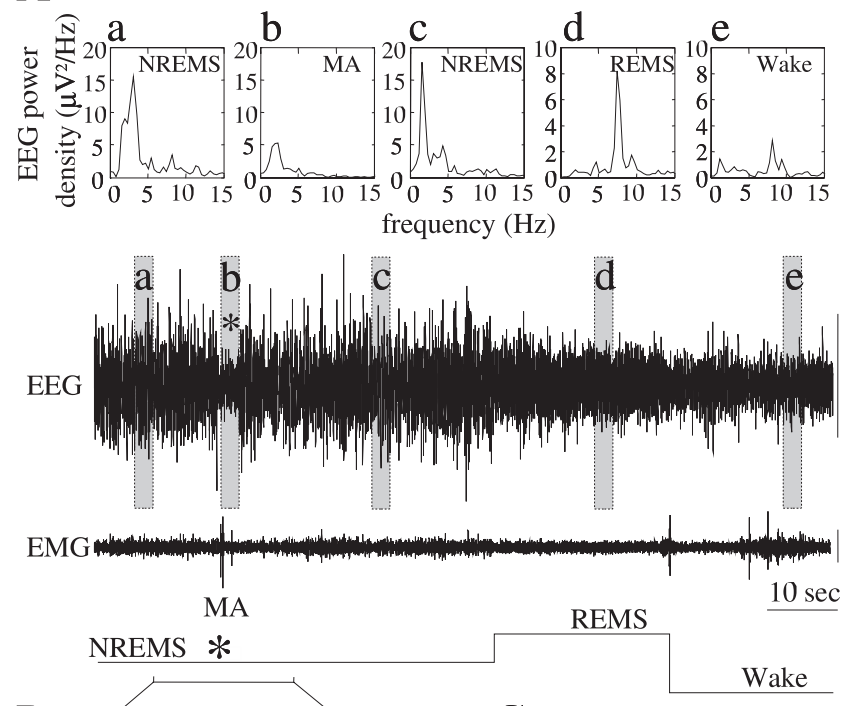

B
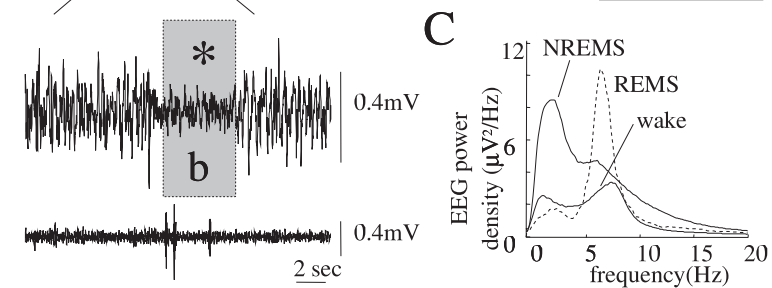

Figure 1. Example of recording and scoring of an MA. A, Polygraphic traces of EEG, EMG, and EEG spectrum in a WT mouse. Calibration bars on the right correspond to $0.4 \mathrm{mV}$. Scoring is performed with three levels: wake, REMS, and NREMS. The transient reduction in EEG power accompanied by a slight EMG activation during NREMS is scored as MA $\left(^{*}\right)$. The power spectrum of the EEG (estimated with 256-point fast Fourier transform and using a Hanning window) for 5 sec segments at the times indicated by the shaded area labeled a-e on the EEG trace are plotted on top in the graphs with the corresponding letters. The spectrum during the MA is characteristic of NREMS but has a low power. $B$, Detail of EEG and EMG for the seconds preceding and following the MA, with low-frequency oscillations of small amplitude during the MA. C, EEG spectral content from a knock-out $\beta 2-/-$ mouse for the three states scored over $24 \mathrm{hr}$. These spectra are similar to the ones of WT mice (C57BL/6J) used in this study and previously (Franken et al., 1998; Huber et al., 2000). The relative amplitude of the peaks was found to vary from animal to animal, presumably depending on the implantation site.

caused a significant decrease in NREMS and REMS during the first hour after the injection (NREMS: vehicle, $31 \pm 2$ min; nicotine $1 \mathrm{mg} / \mathrm{kg}, 19 \pm 3 \mathrm{~min}, p<0.01$; and nicotine $2 \mathrm{mg} / \mathrm{kg}, 24 \pm$ $5 \mathrm{~min}, p<0.05$; REMS: vehicle, $2.6 \pm 0.4 \mathrm{~min}$; nicotine $1 \mathrm{mg} / \mathrm{kg}$, $0.5 \pm 0.3 \mathrm{~min}, p<0.001$; nicotine $2 \mathrm{mg} / \mathrm{kg}, 0.9 \pm 0.5 \mathrm{~min}, p<$ $0.001)$. Thereafter, a "rebound" decrease in wake could be observed during the second hour (Fig. 2), and this effect was associated with an increase in NREMS amounts (vehicle, $39 \pm 2 \mathrm{~min}$; nicotine $1 \mathrm{mg} / \mathrm{kg}, 46 \pm 1 \mathrm{~min}, p<0.001$; nicotine $2 \mathrm{mg} / \mathrm{kg}, 45 \pm$ $1 \mathrm{~min}, p<0.05)$. No remaining effect was observed in the third and fourth hours after the injection. In knock-out $\beta 2-/-$ animals, nicotine failed to change the amounts of wake and sleep at any dose tested in the first $2 \mathrm{hr}$. However, a consistent decrease in wake was observed during the third hour for the highest dose of nicotine (vehicle, $17 \pm 3 \mathrm{~min}$; nicotine $2 \mathrm{mg} / \mathrm{kg}$, $7 \pm 1 \mathrm{~min}, p<$ $0.001)$. This effect was not further investigated. These results indicate that the awakening effects of nicotine are mediated by $\beta 2$-containing nAChRs ( $\left.\beta 2^{\star} \mathrm{nAChRs}\right)$.

NREMS and REMS are more stable in $\beta 2-/-$ mice Under basal conditions, both groups of mice exhibited a diurnal sleep-wake rhythm characteristic of C57BL/6J mice (Franken et

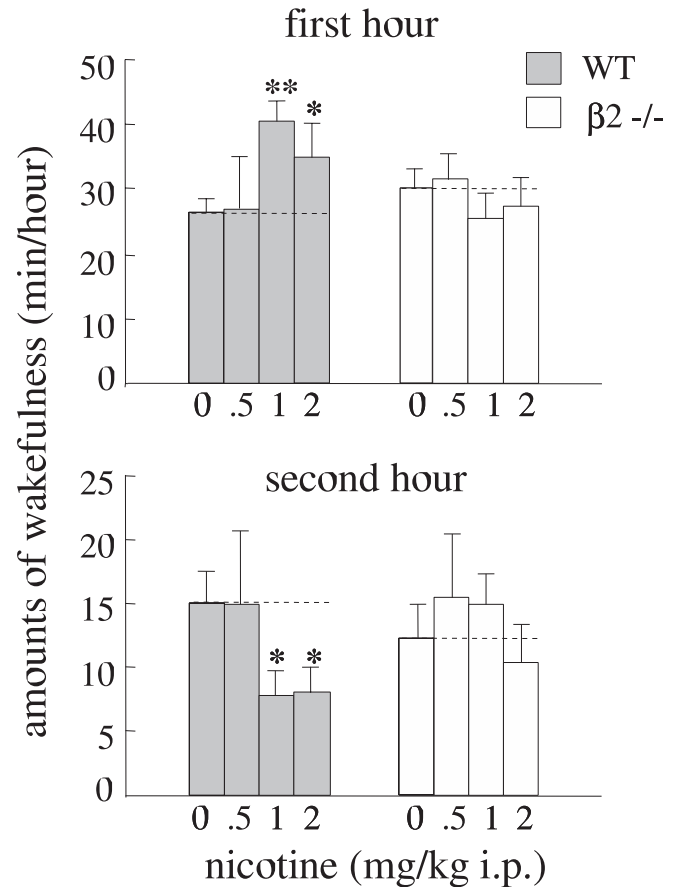

Figure 2. Nicotine injection (intraperitoneally) alters the amount of wake in WT but not in $\beta 2-/-$ mice. The injections were performed at 10:00 A.M. Compared with saline injection (0 on abscissa), nicotine at $1 \mathrm{mg} / \mathrm{kg}$ (10 WT; $7 \beta 2-/-$ ) and $2 \mathrm{mg} / \mathrm{kg}$ (8 WT; $7 \beta 2-/-$ ) increases the amount of wake during the first hour. A rebound decrease is observed in the second hour in WT but not in $\beta 2-1-$ mice. Nicotine $(0.5 \mathrm{mg} / \mathrm{kg})$ does not affect the amount of wake (5 WT; $6 \beta 2-/-$ ). The data are taken from 14 WT and $14 \beta 2-/-$ mice. ${ }^{*} p<0.05$; ${ }^{* *} p<$ 0.01 ; significantly different from control; paired Student's $t$ test.

al., 1999; Huber et al., 2000). WT $(n=14)$ and $\beta 2-/-(n=18)$ mice expressed similar amounts of wake $\left(F_{(1,30)}=0.020 ; p=\right.$ $0.89)$, NREMS $\left(F_{(1,30)}=0.022 ; p=0.88\right)$, and $\operatorname{REMS~}\left(F_{(1,30)}=\right.$ $0.0037 ; p=0.95)$.

Although the amounts of various vigilance states were similar, the organization of sleep differed significantly between the strains (Figs. 3, 4). REMS episodes were markedly longer in $\beta 2-1-$ animals $\left(F_{(1,30)}=11.5 ; p=0.0019\right)$ (Fig. 3 ), notably during the night. The fragmentation of NREMS by short awakenings (up to $15 \mathrm{sec}$ of wake between NREMS episodes) was similar in both strains (Fig. $4 A)\left(F_{(1,30)}=0.82 ; p=0.37\right)$. In contrast, the fragmentation of NREMS by MA (expressed as the number of MA per minute of NREMS) was significantly lower in $\beta 2-/-$ animals $\left(F_{(1,30)}=17.2 ; p=0.0003\right.$ ) (Fig. $4 A$ ). Interestingly, the duration of sustained NREMS segments, defined as segments of NREMS not interrupted by MA, was particularly longer in $\beta 2-/-$ animals for segments of sleep preceding REMS (Fig. 4B). The sleep that immediately precedes REMS (pre-REMS) is characterized by shifts in the EEG power content (Benington and Heller, 1994; Franken et al., 1998; Franken, 2002) (Fig. 4C). WT and $\beta 2-1-$ mice showed a similar time course of spectral changes in pre-REMS (Fig. 4C), indicating that the difference between the strains in the duration of sustained NREMS before REMS is more likely to correspond to a stabilization of NREMS rather than a change in the duration of the pre-REMS. Overall, these results indicate that REMS and NREMS are more stable in $\beta 2-/-$ animals.

\section{Similarity of events fragmenting NREMS in WT and B2-1- mice}

The MA interrupting the NREMS were composite events associating a diminution in EEG power with several peripheral signs 


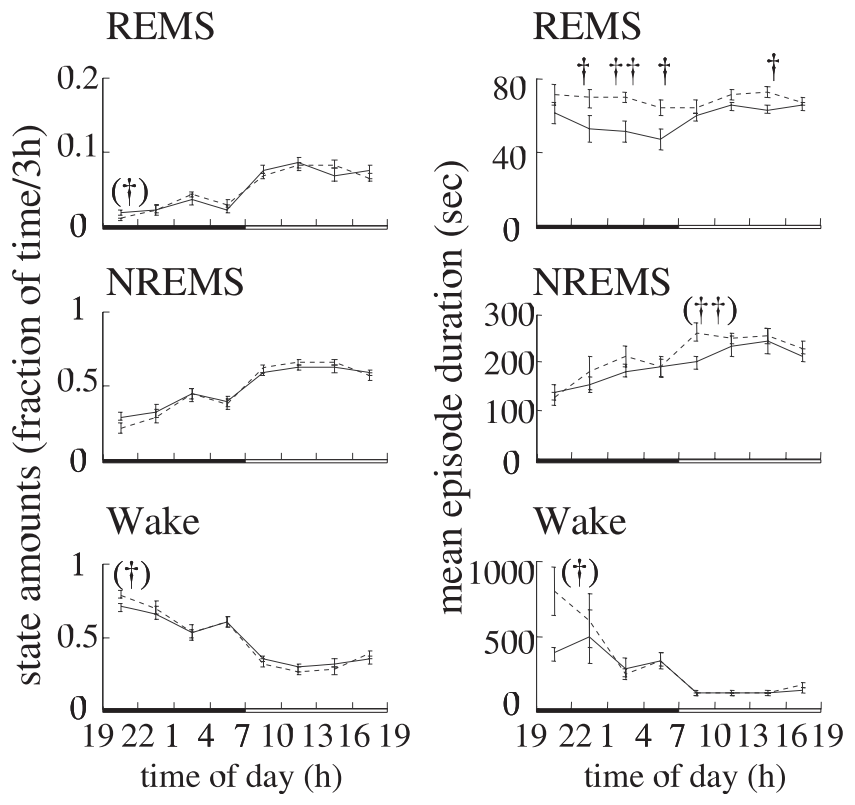

Figure 3. $\quad \beta 2-/-$ mice express normal amounts of Wake, NREMS, and REMS but longer episodes of REMS. Left column, WT and $\beta 2-1-$ mice exhibit similar amounts (fraction of time) of Wake, NREMS, and REMS. The data are expressed for $3 \mathrm{hr}$ time bins (but similar results are obtained for $1 \mathrm{hr}$ time bins). When ANOVA failed to detect any difference (see Results), significance with the $t$ test is indicated in parenthesis. Right column, The duration of REMS episodes is longer in $\beta 2-/-$ mutants than in WT mice, whereas NREMS and Wake episodes have a similar duration in both strains. The data are taken from 14 WT and $18 \beta 2-/-$ mice. ${ }^{\dagger} p<0.05 ;{ }^{{ }^{\dagger}} p<0.01 ;{ }^{{ }^{+\dagger}} p<0.001$; significant difference between strains; unpaired Student's $t$ test.

such as EMG activation, heart beat acceleration, and respiratory events (Fig. 5A). The relationship between EEG power changes and EMG activation was assessed in a subset of recordings with little or no artifacts on the EMG channel during MA. MA were associated with a neck EMG activation in $\sim 85 \%$ of the cases (WT, $87.3 \pm 5.5 \%(n=7) ; \beta 2-/-, 86.6 \pm 2.4 \%(n=8) ; p=0.90)$. The onset of EMG activation coincided generally with the beginning of the reduction in EEG power (Fig. 5B, left). EMG activation in NREMS was associated with a similar reduction in EEG power in WT and $\beta 2-/-$ animals [average EEG power over $2 \mathrm{sec}$ centered on 3-15 sec long EMG activation was: WT, $37.7 \pm 3.1 \%$ $(n=7) ; \beta 2-/-, 40.2 \pm 3.5 \%(n=8) ; p=0.46$, of the baseline EEG power taken 20-30 sec before EMG activation] with no increase of power in the $\theta$ band visible in averaged spectrograms (data not shown). During NREMS, EMG activation was thus associated with a similar drop in EEG power in both strains.

The observation that hypopnea results in less behavioral activation in $\beta 2-/-$ mutants than in WT mice (Cohen et al., 2002) raised the hypothesis that the decreased NREMS fragmentation observed in $\beta 2-/-$ mice might result from a diminution of transient stage shifts in response to spontaneous hypopnea/apnea during NREMS. This led us to run a series of experiments combining respiration monitoring with polygraphic recordings.

Spontaneous apneas in NREMS rarely lasted more than $1 \mathrm{sec}$ [average duration: WT, $0.68 \pm 0.03 \mathrm{sec}(n=7) ; \beta 2-/-, 0.75 \pm$ $0.03 \sec (n=5) ; p=0.11]$ and were associated with a mild reduction of EEG power (Fig. $5 B$, right) [average EEG power over $2 \mathrm{sec}$ around the apnea was, respectively: WT, $81.5 \pm 7.4 \%(n=$ $7) ; \beta 2-/-, 69.9 \pm 3.1 \%(n=5) ; p=0.17$ of the EEG power 30-20 sec before the apnea]. In contrast, sighs in NREMS were generally associated with a strong reduction of EEG power of similar amplitude in both strains (Fig. 5B, middle) [average EEG power over $2 \mathrm{sec}$ around the sigh was: WT, $43.0 \pm 2.9 \%(n=7)$ $\beta 2-/-, 42.7 \pm 3.2 \%(n=5) ; p=0.96$, of the EEG power $30-20$ sec before the sigh] but tended to be followed by a stronger decrease in EEG power in $\beta 2-1-$ mice (Fig. $5 B$ ). In both WT and $\beta 2-/-$ mice, the sighs (and apneas) occurred in an average of $5-10 \mathrm{sec}$ after the beginning of the decline in EEG power (Fig. $5 B$ ), and average spectrograms failed to evidence a change in EEG spectrum during these events. The MA were accompanied by sighs in half of the cases [WT, $48.3 \pm 4.8 \%(n=7) ; \beta 2-/-$, $55.7 \pm 11.3 \%(n=5) ; p=0.48]$ and with spontaneous apnea in a smaller number of cases [WT, $15.9 \pm 4.7 \%(n=7) ; \beta 2-/-$, $21.0 \pm 4.7 \%(n=5) ; p=0.42]$. In summary, apneas had little effect by themselves on EEG. The main respiratory events associated with the MA were the sighs, and these events occurred after the decline in EEG power had started. An abnormal coupling between respiration and MA generation in $\beta 2-/-$ mice is thus unlikely to be the cause of the lower NREMS fragmentation in these mutants compared with WT mice.

The increase in heart rate tended to occur in a late phase of the MA. Sigh-triggered average showed that the peak of heart rate was reached within the second that follows the sighs (data not shown), with a similar delay in WT and $\beta 2-/-$ mice $(p=0.16)$. Interestingly, the amplitude of the maximal increase in beat per min (bpm) was relatively larger in $\beta 2-/-$ mice [increase at peak relative to the baseline heart rate taken $30-20 \mathrm{sec}$ before the sigh: $\mathrm{WT},+13 \pm 2 \%(n=5) ; \beta 2-/-,+29 \pm 3 \%(n=5) ; p<0.01]$, but this could be caused in part by the lower baseline in $\beta 2-/-$ animals [WT, $548 \pm 17 \mathrm{bpm}(n=5) ; \beta 2-/-, 459 \pm 10 \mathrm{bpm}$ $(n=5) ; p<0.01]$. In summary, the $\beta 2-/-$ animals exhibited a normal or slightly enhanced sympathetic activation during the MA.

\section{Sleep deprivation is followed by a marked reduction in NREMS fragmentation in $\boldsymbol{\beta} 2-/-$ mice}

Sleep deprivation increases the sleep pressure and challenges the homeostatic processes of sleep regulation. After a $6 \mathrm{hr}$ sleep deprivation (by enriching the environment and by gentle handling), WT $(n=8)$ and $\beta 2-/-(n=7)$ animals showed a similar transient increase in the EEG power in the $\delta$ band, a marker of NREMS homeostasis (Borbely and Achermann, 1999), during the first hour of recovery (Fig. $6 A$ ) (WT, $+43 \pm 15 \%, p<0.05$; $\beta 2-/-,+55 \pm 15 \% ; p<0.01$; no significant difference between the strains: $\left.F_{(1,13)}=0.067 ; p=0.80\right)$. Sleep deprivation also influenced sleep episode duration; REMS episode duration ( $\mathrm{Hu}-$ ber et al., 2000) increased similarly in WT and $\beta 2-/-$ mice during the first $3 \mathrm{hr}$ of the recovery period (Fig. $6 \mathrm{~B}$ ) (WT, $+51 \pm$ $17 \% ; \beta 2-/-,+40 \pm 19 \% ; p=0.62$ ). Moreover, sleep deprivation caused a marked decrease in the frequency of short awakenings (Franken et al., 1999; Huber et al., 2000) during the first $3 \mathrm{hr}$ period of recovery $(\mathrm{WT},-39 \pm 6 \% ; \beta 2-/-,-37 \pm 2 \% ; p=$ 0.84 ), these short awakenings occurring primarily between REMS and NREMS. In contrast, the fragmentation of NREMS by MA was strongly decreased in $\beta 2-/-$ but not in WT animals (Fig. 6C) (first 3 hr: WT, $-10 \pm 12 \%$; $\beta 2-/-,-47 \pm 5.9 \%$; $p<$ $0.05)$. Overall, the $\beta 2-/-$ animals exhibited normal homeostatic changes in response to sleep deprivation with the exception of a marked decrease in NREMS fragmentation by MA.

\section{Immobilization stress disrupts sleep in $\beta 2-/-$ mutants}

Depending on its intensity and duration, a stress may either promote or disrupt sleep (Marinesco et al., 1999). We examined whether the stabilization of sleep could also be promoted in $\beta 2-/-$ animals after an immobilization stress (Fig. 7) as de- 
A

B

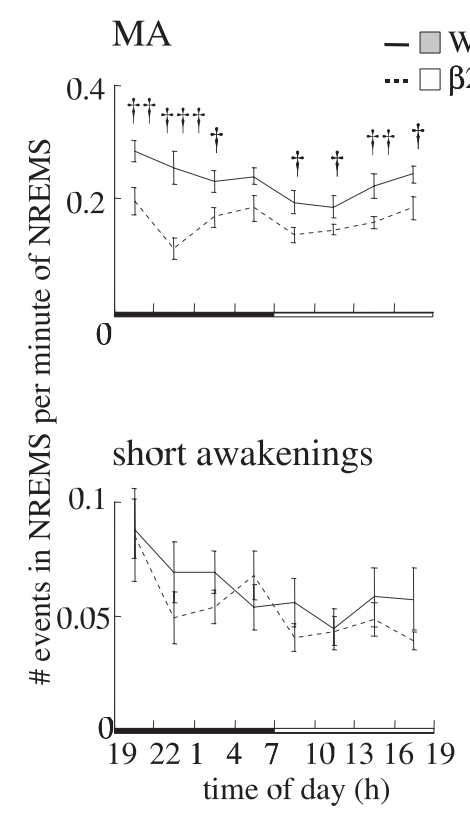

C sustained NREMS (no MA) all episodes episodes before
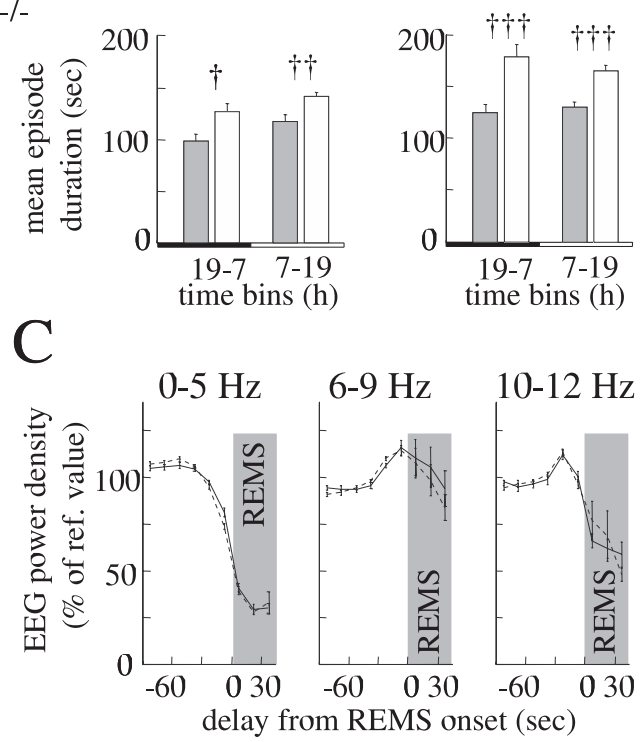

Figure 4. The NREMS in $\beta 2-1-$ mice is less fragmented by MA, notably for the NREMS immediately preceding REMS. $A$, The fragmentation of NREMS by MA is significantly lower in $\beta 2-/-$ compared with WT mice, whereas the fragmentation of NREMS by short awakenings is similar in both strains. $B$, The segments of sustained NREMS (i.e., devoid of MA) are significantly longer in $\beta 2-I-$ notably for the NREMS that immediately precedes REMS.C, The power content of the EEG shows a similar time course in both strains during the 30 sec that immediately precedes REMS, indicating that the pre-REMS is not altered in $\beta 2-1-$ mice. The data are taken from 14 WT and $18 \beta 2-1-$ mice. ${ }^{\dagger} p<0.05 ;{ }^{{ }^{\dagger}} p<0.01 ;{ }^{\dagger+t} p<0.001$; significant difference between strains; unpaired Student's $t$ test.

scribed previously for WT mice with the same genetic background (Meerlo et al., 2001). One hour immobilization of WT mice $(n=9)$ significantly increased the amount of REMS during the following dark period $\left(F_{(1,56)}=7.76 ; p=0.0073\right)$ but affected neither the amount nor the fragmentation of NREMS. When subjected to the same stress, $\beta 2-/-$ animals $(n=8)$ exhibited a different response during the following night, notably with no increase in the amounts of REMS $\left(F_{(1,49)}=0.19, p=0.66\right.$; with a significant genotype-treatment interaction $F_{(1,105)}=4.48, p=$ 0.037 ) (Fig. 7A) and an increased fragmentation of NREMS by MA $\left(F_{(1,48)}=14.0, p=0.0005\right.$; with a significant genotypetreatment interaction $\left.F_{(1,103)}=14.7, p=0.0002\right)$ (Fig. $7 B$ ). There was also a small increase in the frequency of short awakenings during the night, but this effect did not differ between the two strains (10:00 P.M. to 7:00 A.M.: WT, $+28.8 \pm 18.3 \%$; $\beta 2-/-$, $+14.1 \pm 14.8 \%$; genotype-treatment interaction term: $F_{(1,103)}=$ $0.89, p=0.35)$. Mild effects of stress on sleep fragmentation could be observed during the following lights-on period (7:00 A.M. to 7:00 P.M.) (Fig. 7B), but they were similar in WT and $\beta 2-/-$ mice. In summary, after a $1 \mathrm{hr}$ immobilization stress, the $\beta 2-/-$ animals displayed a reduction in the quality of NREMS instead of the increase in REMS that occurs in WT animals.

The immobilization stress is known to induce a large response of the stress hormonal system. The REMS rebound is thought to require a return of corticosterone to baseline levels (Boutrel et al., 2002). We then examined the time course of serum corticosterone levels after the immobilization. We measured the corticosterone in WT and $\beta 2-/-$ mice ( $n=8$ for each condition) at the end and $4 \mathrm{hr}$ after an immobilization stress. Both genotypes showed a similar immediate response of corticosterone to the stress (Fig. 7C). These levels were decreased in the WT and REMS

$\beta 2-/-$ mice $4 \mathrm{hr}$ after the immobilization session, but they remained higher than control values in the $\beta 2-1-$ mice $(p<$ 0.05 ) (Fig. 7C). Thus, the response of the hormonal system was not terminated in $\beta 2-1-$ mice at the time where the hormonal response was terminated, and the REMs rebound occurred in WT mice.

\section{Discussion}

Our results demonstrate that $\beta 2^{\star} \mathrm{nAChRs}$ are involved in processes that control NREMS and REMS stability (but not homeostasis): generating the MA that fragment NREMS, limiting REMS continuity, and facilitating the sleep-promoting effects of an acute stress.

\section{$\boldsymbol{\beta} 2^{\star} \mathrm{nAChRs}$ promote waking states}

As previously reported in the rat (SalinPascual et al., 1999), the injection of nicotine produced an increase in the time spent in the awake state in WT mice. In the latter species, it also caused a rebound increase in sleep during the second hour after the injection. This secondary change was not described in the rat and might correspond to either a recovery from the sleep deficit caused by nicotine in the first hour or a delayed pharmacological action of nicotine and its metabolites. These two effects of nicotine were not observed in $\beta 2-/-$ mutants. In contrast with these pharmacological data, the amounts of spontaneous wake, NREMS, and REMS were similar in WT and $\beta 2-/-$ mice, thereby suggesting that the physiological activation of $\beta 2^{\star}$ nAChRs does not contribute critically to overall sleep regulation. Instead, our experiments indicate that $\beta 2^{\star} \mathrm{nAChRs}$ play a role in shaping sleep episodes. Notably, the frequency of interruptions of NREMS by MA, particularly before REMS, is decreased, whereas REMS duration is increased in $\beta 2-/-$ animals.

\section{$\beta 2^{\star} \mathrm{nAChRs}$ are involved in transient reduction of NREMS depth}

NREMS is segmented by MA, transient events characterized by a decreased EEG power accompanied by polygraphic changes with notably EMG activation, sighs, and heart beat acceleration. Our results show that the occurrence of such events is reduced in $\beta 2-/-$ animals, indicating an involvement of $\beta 2^{\star} n A C h R s$ in their generation. The combination of EEG changes, and peripheral polygraphic activity in these events is reminiscent of microarousals observed in humans (for review, see Halász, 1998). They occur typically at a frequency of $\sim 0.2-0.3$ events per minute (one every 3-5 min of NREMS), which matches the frequency of micro-arousals in human sleep (Halász, 1998; De Gennaro et al., 2001). Their onset is followed by breathing irregularities as observed in humans for NREMS arousals elicited by sounds (Khoo et al., 1996). Events that could be similar to our MA have been described previously in the rat as "arousal-like period" (Roldán et al., 1963), "low-amplitude sleep" (Bergmann et al., 1987), "brief awakenings" (Franken et al., 1991), or "sleep small-amplitude irregular activity" and "a state of increased alertness" described 
by Jarosiewicz et al. (2002). We propose that the MA described herein correspond to micro-arousals in mice.

The lower frequency of MA during NREMS observed in $\beta 2-/-$ mice resembled the deficit in putative arousals (detected by artifacts in the respiratory pressure signal) that was reported in the same mutant mice after a hypoxic challenge (Cohen et al., 2002). However, our plethysmographic recordings showed that the sighs, which are the main respiratory events observed during the arousals, clearly occurred several seconds after the beginning of the decline in EEG power. Still, the protective awakenings evoked by a hypoxic challenge observed by Cohen et al. (2002) might recruit the same pathway as the MA described in our study.

Sleep deprivation enhances sleep pressure. It is followed by an enhancement of EEG synchronization illustrated by an increased power in the $\delta$ band (Borbely and Achermann, 1999). WT and $\beta 2-1-$ mice exhibited the same pattern of increased synchronization with similar amplitude and time course as published for the C57BL/6J mouse strain (Franken et al., 1999; Huber et al., 2000), indicating that $\beta 2^{\star}$ nAChRs are not involved in this phenomenon. In accordance with previous observations (Franken et al., 1999; Huber et al., 2000), a $6 \mathrm{hr}$ sleep deprivation also reduced the number of short awakenings both in WT and $\beta 2-/-$ mice. In $\beta 2-/-$ mutants, sleep deprivation further reduced the frequency of MA by $\sim 40 \%$ compared with WT. Therefore, instead of lowering the values of sleep fragmentation in WT mice down to those in $\beta 2-/-$ mutants, sleep deprivation tended, rather, to exaggerate the difference between WT and $\beta 2-/-$ mice.

Our results indicate that nAChRs are involved in the phasic expression of arousal-promoting mechanisms (Halász, 1998; Terzano and Parrino, 2000) observed in NREMS in normal conditions and after sleep deprivation. Interestingly, nAChRs have also been proposed to regulate (Vazquez et al., 1996) and to relay in the cat (Hu et al., 1988) the pontogeniculo-occipital waves, a phasic activity observed in REMS. Whether the transient activity in REMS and the transient arousals in NREMS share some common mechanisms remains to be investigated.

Our results might also be relevant to frontal lobe nocturnal epilepsies (FLNE) in humans that are caused by the hyperfunction of $\alpha 4$ or $\beta 2^{\star}$ nAChRs (Itier and Bertrand, 2002) and that tend to occur in a stage of light sleep with intense cyclic micro-arousals activity (cyclic alternating pattern) (Terzano and Parrino, 2000). Indeed, in some cases of FLNE, a direct temporal correlation was found between micro-arousals and epileptic manifestations

A

B $t$ test.
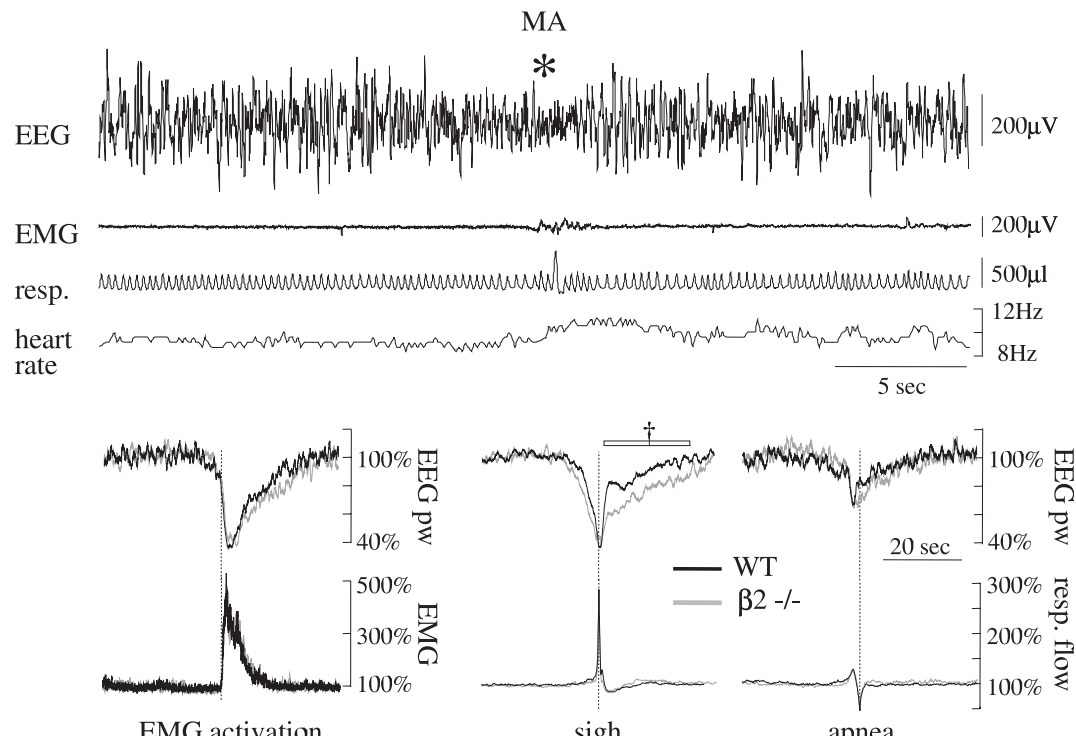

Figure 5. Similarity of the MA in relation to peripheral signs (notably breathing) in WT and $\beta 2-/-$ mice. $A$, Example of polygraphic recording from a WT mouse showing an MA combining a reduction in EEG power with EMG activation, changes in respiration (resp.), and an increase in heart rate. $B$, EEG in WT and $\beta 2-1-$ mice exhibits a similar reduction in power during EMG activation and sighs. Left, Events of EMG activation lasting 3-15 sec were used to compare the associated reduction in EEG power. EEG traces were aligned around the beginning of EMG activation (30-100 events per animal in the interval 7-13 hr) and averaged for each animal. These traces were then normalized to the average of $20-30$ sec preceding the EMG activation, pooled together, and smoothed by run-average with a 1 sec square window (left, top). The same treatment (without the run-average) was applied in parallel to the EMG traces (left, bottom) for seven WT and eight $\beta 2-1-$ mice during NREMS. The same analysis was performed for EEG power and respiration flow (see Materials and Methods) around sighs and isolated apneas monitored in plethysmographic experiments (right). These data are taken from seven WT and five $\beta 2-/-$ mice. The reduction of EEG power begins shortly before the onset of the EMG activation, whereas sighs and apneas occur clearly after the decline in EEG power has started. The apneas are associated with a minor reduction in EEG power. The bar indicates a significant difference $\left({ }^{\dagger} p<0.05\right.$; unpaired $t$ test) between the normalized traces smoothed by run-average with a $1 \mathrm{sec}$ window.
A

NREMS delta power

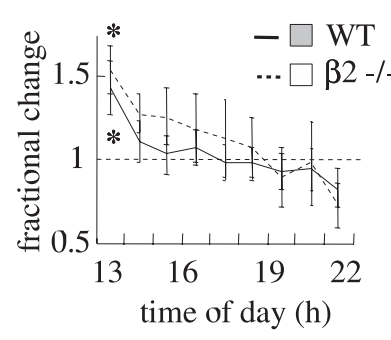

B

REMS episode duration

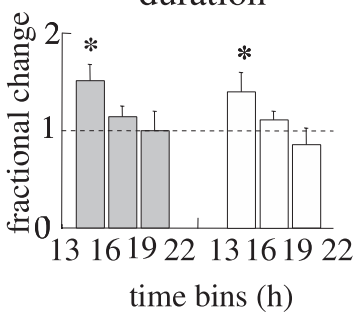

MA occurrence

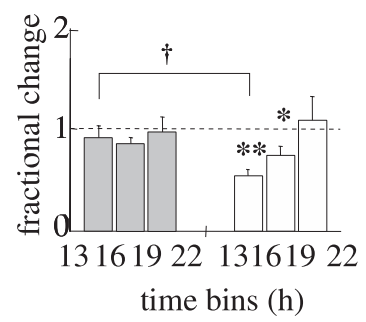

Figure 6. Effects of a $6 \mathrm{hr}$ sleep deprivation (7:00 A.M. to 1:00 P.M.) in WT and $\beta 2-/-$ mice. $A$, B, Similarity in WT and $\beta 2-/-$ mice of the increase in $\delta$ power (a marker of NREMS pressure) and of REMS episode duration (an index of stabilization) during recovery from sleep deprivation. The increase in $\delta$ power during the 1:00 -2:00 P.M. interval is significant, but equivalent, in both strains (see Results). The increase in duration of REMS episode, a normal consequence of sleep deprivation, is limited to the first $3 \mathrm{hr}$ bin and is similar in both strains. C, Sleep deprivation is followed by a marked reduction in NREMS fragmentation by MA during the first $3 \mathrm{hr}$ of recovery in $\beta 2-/-$ mice. Fractional change is calculated relative to controls. ${ }^{*} p<0.05 ;{ }^{* *} p<0.01$; significantly different from control; paired Student's $t$ test. ${ }^{\dagger} p<0.05$; significant difference between strains, unpaired Student's

(Zucconi and Ferini-Strambi, 2000). The understanding of the physiological involvement of $\beta 2^{\star} \mathrm{nAChRs}$ in the phasic activity in NREMS might thus help to clarify the causes of nocturnal epilepsies caused by mutations in nAChRs subunits encoding genes.

$\beta 2^{\star}$ nAChRs participate in the stabilization of REMS episodes REMS episodes in $\beta 2-/-$ mutants have a longer duration but are also preceded by a longer period of sustained NREMS (not 
A REMS amounts
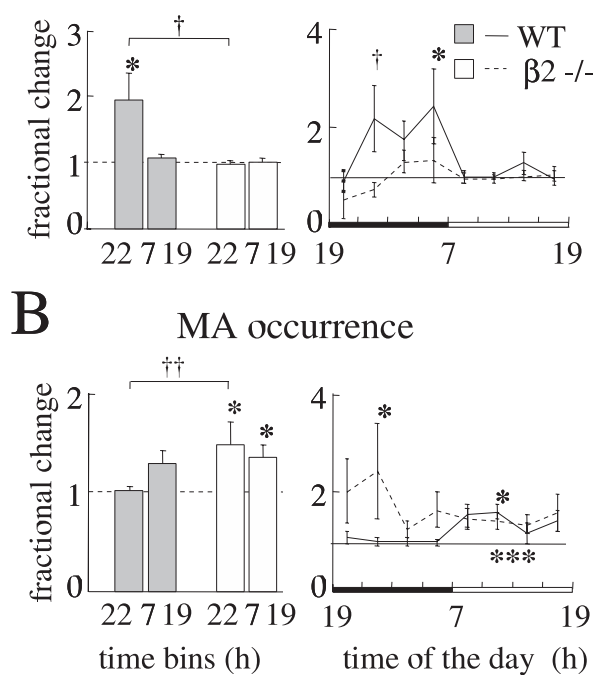

18:00 19:00 (T0) 23:00 (T0+4h)
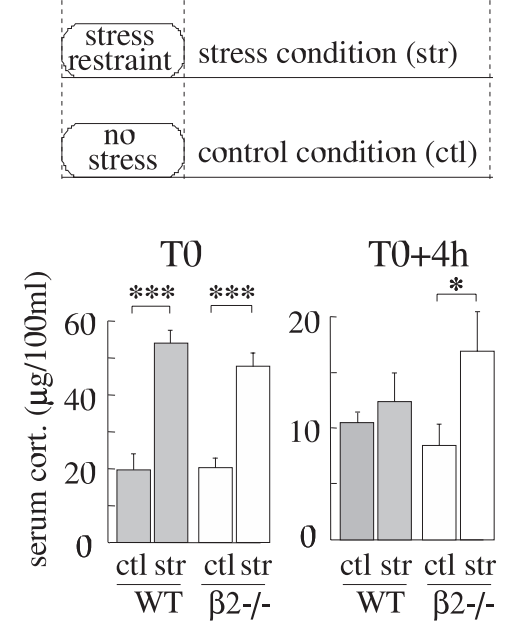

\section{$\mathrm{T} 0+4 \mathrm{~h}$}

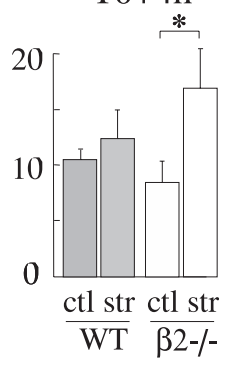

Figure 7. Differences in the impact of a $1 \mathrm{hr}$ immobilization stress in WT and $\beta 2-/-$ mice. $A$, The immobilization stress (6:00-7:00 P.M.) increases REMS in WT mice and disrupts NREMS in $\beta 2-1-$ mice during the following night. $A, B$, The fractional changes in the amount of REMS $(A)$ and in NREMS fragmentation by MA $(B)$ are plotted for $9-12 \mathrm{hr}$ time bins (left) and $3 \mathrm{hr}$ time bins (right). Fractional change is calculated relative to controls. C, Time course of corticosterone after an immobilization stress. The serum corticosterone has been measured in WT and $\beta 2-1-$ mice immediately (T0) or $4 \mathrm{hr}$ after (T0 $+4 \mathrm{hr}$ ) the end of the stress (str) and is compared with the levels in control mice with the same genotype killed at the same hours (ctl). Corticosterone levels is increased similarly in $\beta 2-/-$ and WT mice just after the stress, but the corticosterone levels remained higher than controls only in $\beta 2-1-$ mice after $4 \mathrm{hr}$. Each data point is from eight animals. ${ }^{*} p<0.05$; ${ }^{* *} p<0.01$; ${ }^{* * *} p<0.001$; significantly different from control; paired Student's $t$ test. ${ }^{\dagger} p<0.05 ;{ }^{+\dagger} p<0.01$; significant difference between strains; unpaired Student's $t$ test.

interrupted by MA) than in WT mice. REMS is a period of intense cholinergic activity in the brain, and REMS termination is classically thought to result from the disinhibition of REM-off neurons such as locus coeruleus noradrenergic neurons or raphe nuclei serotoninergic neurons (Steriade and McCarley, 1990). Indeed, both of these structures express high amounts of $\beta 2^{\star} \mathrm{nAChRs}$ (Léna et al., 1999; Marubio et al., 1999), which might contribute to the disinhibition of aminergic neurons and would thus trigger earlier REMS termination in WT mice compared with $\beta 2-1-$ mutants.

Moreover, according to models of REMS homeostasis (Benington and Heller, 1994; Vivaldi et al., 1994; Franken, 2002), the longer REMS episodes observed in $\beta 2-/-$ mutants would reset the REMS pressure and delay the onset of the next REMS episode, an effect that would be reflected in the longer sustained NREMS preceding REMS in the $\beta 2-/-$ mutants. Thus, a deficit in REMS termination could result in alterations of the short-term homeostasis of the REMS-NREMS cycle consistent with our observations in $\beta 2-1-$ mice.

\section{NREMS disruption by acute immobilization stress in $\boldsymbol{\beta} 2-/-$ animals}

Nicotine is a positive effector of the hypothalamo-pituitaryadrenal axis (Matta et al., 1998), and it was thus expected that an acute stress would have less effect on sleep in $\beta 2-/-$ mutants than in WT mice. A $1 \mathrm{hr}$ immobilization stress in the rodent is normally followed by an increase in REMS amounts in the following hours (Rampin et al., 1991; Boutrel et al., 2002). Such an effect was not observed in $\beta 2-1-$ mice, and an increased fragmentation of NREMS was observed instead. A similar pattern has been described in the rat after a prolonged restraint stress $(4 \mathrm{hr})$ that triggered a delayed return of corticosterone levels to baseline, a suppression of the REMS rebound and a light reduction of NREMS episode duration (Marinesco et al., 1999). The REMS rebound is also suppressed by a chronic stress and is then accompanied by a decrease in sleep continuity (Kant et al., 1995). The pattern observed in $\beta 2-/-$ mutants might thus correspond to a slower poststress decline of corticosterone levels (Boutrel et al., 2002) as it has been suggested already for these animals (Zoli et al., 1999). Indeed, a cholinergic deafferentation of the hippocampus results in a delay in the decline of corticosterone levels after a stress episode (Han et al., 2002). Consistently, our measures of corticosterone $4 \mathrm{hr}$ after the termination of the stress evidenced a sustained increase in corticosterone plasma levels of $\beta 2-1-$ mice that was not observed in WT mice. Therefore, the delayed decline of corticosterone levels after a stress episode might result in the absence of REMS rebound observed in our study. Alternatively, the REMS rebound and the maintenance of NREMS continuity might require the release of prolactin (Meerlo et al., 2001) triggered by the recruitment of $\beta 2^{\star}$ nAChRs (Matta et al., 1998).

\section{Conclusion, perspectives}

The main finding of this work is the existence of a contribution of nAChRs to the organization of sleep, notably to the regulation of transient events occurring during NREMS (which are putative micro-arousals), to the duration and onset of REMS episodes, and to the REMS-promoting effects of stress.

In humans, micro-arousals form a heterogeneous population of events of varying structure and intensity (Halász, 1998; Sforza et al., 2000). Additional characterization of the corresponding events in mice and of their neurobiological mechanisms should help to clarify the contribution of $\beta 2^{\star}$ nAChRs to sleep regulation and potentially to SIDS and to the autosomal dominant FLNE caused by mutations in nAChRs subunits encoding genes.

\section{References}

Benington JH, Heller HC (1994) REM-sleep timing is controlled homeostatically by accumulation of REM-sleep propensity in non-REM sleep. Am J Physiol 266:R1992-R2000.

Bergmann BM, Winter JB, Rosenberg RS, Rechtschaffen A (1987) NREM sleep with low-voltage EEG in the rat. Sleep 10:1-11.

Borbely AA, Achermann P (1999) Sleep homeostasis and models of sleep regulation. J Biol Rhythms 14:557-568.

Boutrel B, Franc B, Hen R, Hamon M, Adrien J (1999) Key role of 5-HT receptors in the regulation of paradoxical sleep as evidenced in $5-\mathrm{HT}_{1 \mathrm{~B}}$ knock-out mice. J Neurosci 19:3204-3212.

Boutrel B, Monaca C, Hen R, Hamon M, Adrien J (2002) Involvement of $5-\mathrm{HT}_{1 \mathrm{~A}}$ receptors in homeostatic and stress-induced adaptive regulations of paradoxical sleep: studies in $5-\mathrm{HT}_{1 \mathrm{~A}}$ knock-out mice. J Neurosci 22:4686-4692.

Cohen G, Han ZY, Grailhe R, Gallego J, Gaultier C, Changeux JP, Lagercrantz H (2002) Beta 2 nicotinic acetylcholine receptor subunit modulates protective responses to stress: a receptor basis for sleep-disordered breathing after nicotine exposure. Proc Natl Acad Sci USA 99:13272-13277. 
De Gennaro L, Ferrara M, Bertini M (2001) EEG arousals in normal sleep: variations induced by total and selective slow-wave sleep deprivation. Sleep 24:673-679.

Franken P (2002) Long-term vs. short-term processes regulating REM sleep. J Sleep Res 11:17-28.

Franken P, Dijk DJ, Tobler I, Borbely AA (1991) Sleep deprivation in rats: effects on EEG power spectra, vigilance states, and cortical temperature. Am J Physiol 261:R198-R208.

Franken P, Malafosse A, Tafti M (1998) Genetic variation in EEG activity during sleep in inbred mice. Am J Physiol 275:R1127-R1137.

Franken P, Malafosse A, Tafti M (1999) Genetic determinants of sleep regulation in inbred mice. Sleep 22:155-169.

Halász P (1998) Hierarchy of micro-arousals and the microstructure of sleep. Neurophysiol Clin 28:461-475.

Han JS, Bizon JL, Chun HJ, Maus CE, Gallagher M (2002) Decreased glucocorticoid receptor mRNA and dysfunction of HPA axis in rats after removal of the cholinergic innervation to hippocampus. Eur J Neurosci 16:1399-1404.

Hu B, Bouhassira D, Steriade M, Deschenes M (1988) The blockage of ponto-geniculo-occipital waves in the cat lateral geniculate nucleus by nicotinic antagonists. Brain Res 473:394-397.

Huber R, Deboer T, Tobler I (2000) Effects of sleep deprivation on sleep and sleep EEG in three mouse strains: empirical data and simulations. Brain Res 857:8-19.

Itier V, Bertrand D (2002) Mutations of the neuronal nicotinic acetylcholine receptors and their association with ADNFLE. Neurophysiol Clin 32:99-107.

Jacky JP (1978) A plethysmograph for long-term measurements of ventilation in unrestrained animals. J Appl Physiol 45:644-647.

Jarosiewicz B, McNaughton BL, Skaggs WE (2002) Hippocampal population activity during the small-amplitude irregular activity state in the rat. J Neurosci 22:1373-1384.

Jasper HH, Tessier J (1971) Acetylcholine liberation from cerebral cortex during paradoxical (REM) sleep. Science 172:601-602.

Jones BE (2003) Arousal systems. Front Biosci 8:S438-S451.

Kant GJ, Pastel RH, Bauman RA, Meininger GR, Maughan KR, Robinson III TN, Wright WL, Covington PS (1995) Effects of chronic stress on sleep in rats. Physiol Behav 57:359-365.

Khoo MC, Koh SS, Shin JJ, Westbrook PR, Berry RB (1996) Ventilatory dynamics during transient arousal from NREM sleep: implications for respiratory control stability. J Appl Physiol 80:1475-1484.

Klink R, de Kerchove d'Exaerde A, Zoli M, Changeux JP (2001) Molecular and physiological diversity of nicotinic acetylcholine receptors in the midbrain dopaminergic nuclei. J Neurosci 21:1452-1463.

Lawrence NS, Ross TJ, Stein EA (2002) Cognitive mechanisms of nicotine on visual attention. Neuron 36:539-548.

Le Novère N, Corringer PJ, Changeux JP (2002) The diversity of subunit composition in nAChRs: evolutionary origins, physiological and pharmacological consequences. J Neurobiol 53:447-456.

Léna C, de Kerchove D’Exaerde A, Cordero-Erausquin M, Le Novère N, del Mar Arroyo-Jimenez M, Changeux JP (1999) Diversity and distribution of nicotinic acetylcholine receptors in the locus ceruleus neurons. Proc Natl Acad Sci USA 96:12126-12131.

Levin ED (2002) Nicotinic receptor subtypes and cognitive function. J Neurobiol 53:633-640.

Marinesco S, Bonnet C, Cespuglio R (1999) Influence of stress duration on the sleep rebound induced by immobilization in the rat: a possible role for corticosterone. Neuroscience 92:921-933.

Marrosu F, Portas C, Mascia MS, Casu MA, Fa M, Giagheddu M, Imperato A, Gessa GL (1995) Microdialysis measurement of cortical and hippocampal acetylcholine release during sleep-wake cycle in freely moving cats. Brain Res 671:329-332.

Martin RJ, Block AJ, Cohn MA, Conway WA, Hudgel DW, Powles AC, Sanders MH, Smith PL (1985) Indications and standards for cardiopulmonary sleep studies. Sleep 8:371-379.
Marubio LM, del Mar Arroyo-Jimenez M, Cordero-Erausquin M, Léna C, Le Novère N, de Kerchove d'Exaerde A, Huchet M, Damaj MI, Changeux JP (1999) Reduced antinociception in mice lacking neuronal nicotinic receptor subunits. Nature 398:805-810.

Matta SG, Fu Y, Valentine JD, Sharp BM (1998) Response of the hypothalamo-pituitary-adrenal axis to nicotine. Psychoneuroendocrinology 23:103-113.

Meerlo P, Easton A, Bergmann BM, Turek FW (2001) Restraint increases prolactin and REM sleep in C57BL/6J mice but not in BALB/cJ mice. Am Physiol Regul Integr Comp Physiol 281:R846-R854.

Pace-Schott EF, Hobson JA (2002) The neurobiology of sleep: genetics, cellular physiology and subcortical networks. Nat Rev Neurosci 3:591-605

Picciotto MR, Zoli M, Léna C, Bessis A, Lallemand Y, Le Novère N, Vincent P Pich EM, Brulet P, Changeux JP (1995) Abnormal avoidance learning in mice lacking functional high-affinity nicotine receptor in the brain. Nature 374:65-67.

Pickworth WB, Fant RV, Butschky MF, Henningfield JE (1997) Effects of mecamylamine on spontaneous EEG and performance in smokers and non-smokers. Pharmacol Biochem Behav 56:181-187.

Rampin C, Cespuglio R, Chastrette N, Jouvet M (1991) Immobilisation stress induces a paradoxical sleep rebound in rat. Neurosci Lett 126:113-118.

Roldán E, Weiss T, Fifková E (1963) Excitability changes during the sleep cycle of the rat. Electroencephalogr Clin Neurophysiol 15:775-785.

Sakai K, Crochet S, Onoe H (2001) Pontine structures and mechanisms involved in the generation of paradoxical (REM) sleep. Arch Ital Biol 139:93-107.

Salin-Pascual RJ, Moro-Lopez ML, Gonzalez-Sanchez H, Blanco-Centurion C (1999) Changes in sleep after acute and repeated administration of nicotine in the rat. Psychopharmacology (Berl) 145:133-138.

Sarter M, Bruno JP (2000) Cortical cholinergic inputs mediating arousal, attentional processing and dreaming: differential afferent regulation of the basal forebrain by telencephalic and brainstem afferents. Neuroscience 95:933-952.

Sforza E, Jouny C, Ibanez V (2000) Cardiac activation during arousal in humans: further evidence for hierarchy in the arousal response. Clin Neurophysiol 111:1611-1619.

Slotkin TA (1998) Fetal nicotine or cocaine exposure: which one is worse? J Pharmacol Exp Ther 285:931-945.

Steriade M, McCarley RW (1990) Brainstem control of wakefulness and sleep. New York: Plenum.

Sutor B, Zolles G (2001) Neuronal nicotinic acetylcholine receptors and autosomal dominant nocturnal frontal lobe epilepsy: a critical review. Pflügers Arch 442:642-651.

Terzano MG, Parrino L (2000) Origin and significance of the cyclic alternating pattern (CAP). Sleep Med Rev 4:101-123.

Tobler I, Gaus SE, Deboer T, Achermann P, Fischer M, Rulicke T, Moser M, Oesch B, McBride PA, Manson JC (1996) Altered circadian activity rhythms and sleep in mice devoid of prion protein. Nature 380:639-642.

Vazquez J, Guzman-Marin R, Salin-Pascual RJ, Drucker-Colin R (1996) Transdermal nicotine on sleep and PGO spikes. Brain Res 737:317-320.

Vivaldi EA, Ocampo A, Wyneken U, Roncagliolo M, Zapata AM (1994) Short-term homeostasis of active sleep and the architecture of sleep in the rat. J Neurophysiol 72:1745-1755.

Yamamoto KI, Domino EF (1965) Nicotine-induced EEG and behavioral arousal. Int J Neuropharmacol 4:359-373.

Zoli M, Léna C, Picciotto MR, Changeux JP (1998) Identification of four classes of brain nicotinic receptors using beta2 mutant mice. J Neurosci 18:4461-4472.

Zoli M, Picciotto MR, Ferrari R, Cocchi D, Changeux JP (1999) Increased neurodegeneration during ageing in mice lacking high-affinity nicotine receptors. EMBO J 18:1235-1244.

Zucconi M, Ferini-Strambi L (2000) NREM parasomnias: arousal disorders and differentiation from nocturnal frontal lobe epilepsy. Clin Neurophysiol 111 [Suppl 2]:S129-S135. 